\title{
High nuclear expression of STAT3 is associated with unfavorable prognosis in diffuse large B-cell lymphoma
}

\author{
Wu ZL', Song YQ', Shi $\mathrm{YF}^{2}$ and J Zhu ${ }^{1 *}$
}

\begin{abstract}
Background: The purpose of the study was to investigate the expression and prognostic value of STAT3 in diffuse large B-cell lymphoma (DLBCL).

Methods: Seventy-four DLBCL patients from 2001 to 2007 were reviewed in the study. The STAT3 expression in their tumor tissues was examined using the immunohistochemistry $(\mathrm{IHC})$ method, and evaluated for its association with clinicopathological parameters.

Results: Strong nuclear staining of STAT3 and phosphorylated-STAT3 ${ }^{\text {tyr705 }}$ (P-STAT3) were observed in 19 cases (25.7\%) and 24 cases (32.4\%), respectively, and the expression levels were highly consistent between them ( $P=$ 0.001). The high nuclear expression of STAT3 was more frequent in the non-germinal center B cell-like (non-GCB) DLBCL than that in the GCB subtype, but not reaching significance $(P<0.061)$. The high nuclear expression of STAT3 was found to be correlated with poor overall survival (OS) $(P=0.005)$. Multivariate Cox regression analysis showed that the STAT3 expression was an independent prognostic factor for DLBCL patients regardless of CHOP or $\mathrm{R}$-CHOP regimen used as the first-line therapy.
\end{abstract}

Conclusion: STAT3 is more frequently expressed in non-GCB DLBCL than that in GCB subtype, and its strong nuclear expression is correlated with poor OS in DLBCL.

\section{Introduction}

Diffuse large B-cell lymphoma (DLBCL) is defined by the World Health Organization (WHO) Classification as a heterogeneous entity, encompassing morphologic and genetic variants, and variable clinical presentations and outcomes [1]. It accounts for $80 \%$ of aggressive lymphomas [2]. International Prognostic Index (IPI) is currently used to predict the prognosis in DLBC [3], but its role is limited[4]. Molecular subtypes of germinal center B cell-like (GCB) and non-germinal center B cell-like (non-GCB) DLBCL subtypes are proposed to stratify the prognosis of DLBCL in addition to the IPI score [5-7], but the application of Rituximab reduced the prognostic difference between the two subtypes [8,9]. More prognostic markers should be identified for DLBCL.

\footnotetext{
* Correspondence: zj@bjcancer.org

'Department of Lymphoma, Peking University School of Oncology, Beijing Cancer Hospital \& Institute; Key Laboratory of Carcinogenesis and

Translational Research (Ministry of Education); Beijing 100142, China

Full list of author information is available at the end of the article
}

The Signal Transducers and Activators of Transcription (STAT) family members play important roles in transcriptional regulation and signal transduction, in which STAT3 plays a critical role in regulation of cell proliferation and survival [10] and is a critical transcription activator in angiogenesis [11]. Hypermethylation silencing of SOCS (the Suppressor of Cytokine Signaling) genes leads to reactivation of STAT pathway, resulting in the resistance to $\mathrm{ABT}-869$, a promising multi-targeted tyrosine kinase inhibitor [12]. STAT pathway also triggers the activity of receptor-associated Janus kinase (JAK) family members and cross-talks with the nuclear factor- $\kappa \mathrm{B}(\mathrm{NF}-\kappa \mathrm{B})$ pathway, which is an important molecular pathogenesis of lymphoma [13]. Thus the STAT family has been actively studied as one of molecular targets for anti-neoplastic therapy [14].

Expression of STAT3 in DLBCL subtypes may be variable according to in vitro studies $[15,16]$. The cell line studies showed that the activated B cell-like (ABC) DLBCL had the highest level of STAT3 mRNA, roughly

\section{C) Biomed Central}


2-fold higher than that in the GCB DLBCL[15,16]. However, the STAT3 expression and its prognostic value in different subtypes of DLBCL tumors were not investigated. In the study, we investigated the expression level and frequency of STAT3 in DLBCL tumors, the difference of STAT3 expression in different DLBCL subtypes, and its prognostic value in DLBCL patients.

\section{Materials and methods}

Patients

Seventy-four consented patients with DLBCL in the Beijing Cancer hospital from 2001-2007 were studied. In 58 patients, 27 cases were treated with R-CHOP and 31 cases with $\mathrm{CHOP}$ as first-line regimens. The clinical research protocol was approved by our Institutional Review Board (IRB). Archived formalin-fixed and paraffin-embedded tumor tissues were obtained from our Department of Pathology.

\section{Immunohistochemical analysis (IHC)}

$4 \mu \mathrm{m}$ thick sections were mounted on APES-coated slides. After dewaxing in xylene and rehydrating in a gradient concentration of ethanol, the slides were immersed in methanol containing $0.3 \%$ hydrogen peroxide for 15 minutes to block endogenous peroxidase activity. All slides were pretreated with an antigen retrieval method by heating the slides in an autoclave in citrate buffer (10 mM, pH 6.0) for 90 seconds except those stained for P-STAT3. EDTA-Tris buffer $(1 \mathrm{mM}$, $\mathrm{pH}$ 9.0) was used for pretreating before P-STAT3 staining. After rinsing in TBS (pH7.6), the specimens were incubated for $2 \mathrm{~h}$ at $37^{\circ} \mathrm{C}$ with anti-STAT3 antibody (sc-7179 rabbit polyclonal antibody, Santa Cruz Biotechnology) for STAT3, anti-P-STAT3 antibody (9145, rabbit monoclonal antibody, Cell Signaling Technology) for P-STAT3 ${ }^{\text {Tyr705 }}$, and antibodies for BCL6, CD10, MUM1 (Santa Cruz Biotechnology). Subsequently, all slides were incubated with Envision HRP antibody working fluid (Dako Company) for 30 minutes at $37^{\circ} \mathrm{C}$, and then developed with DAB- $\mathrm{H}_{2} \mathrm{O}_{2}$ solution (Dako Company). The cell nuclei were stained with Meyer's hemotoxylin. The normal tonsil tissue was used as a negative control and breast cancer tissue stained positive was used as a positive control for STAT3 and P-STAT3 in all experiments. For technical details, see the manufacturer's instructions for each reagent.

IHC staining was evaluated by two independent experienced pathologists, who were blinded to the clinical data. As for the nuclear staining, at least 100 tumor cells per specimen were counted and only specimens showing moderate to strong immunoreactivity were considered positive. Staining was considered strong positive when $>75 \%$ of tumor cell nuclei were stained positive for STAT3 and > 30\% of tumor cell nuclei for
P-STAT3. Specimens stained positive for STAT3 $\leq 75 \%$ and $\leq 30 \%$ for P-STAT3 were considered weak immunoreactivity.

\section{Statistics}

The Chi-square test was used to analyze the consistence of expressions of STAT3 in nucleus and P-STAT3. Correlation analysis of the STAT3 expression and the PSTAT3 level with clinicopathological variables was performed by two-sided Chi-square test. Kaplan-Meier method was used to estimate difference of OS. OS was defined as the time from diagnosis to death or the last follow-up. The Cox regression model was used to evaluate the prognostic value. The statistical software SPSS16.0 was used for all the statistical analysis.

\section{Results}

Patient characteristics

All patients had complete follow-up information from the Tumor Registry Office in our hospital. The clinicopathological characteristics are summarized in Table 1. Fifty five patients were younger than 60 years old. Male and female patients were 30 and 44, separately. Twenty nine patients were diagnosed with $\mathrm{B}$ symptoms, 50 patients had stage III-IV diseases and 50 patients were diagnosed with the non-GCB subtype.

\section{STAT3 expression}

Among the 74 patients, 66 cases $(89.19 \%)$ had the STAT3 expression, including 19 cases (25.7\%) with strong nuclear staining of STAT3, and 24 cases $(32.4 \%)$ with strong nuclear staining of P-STAT3. Representative staining outcomes were shown in Figure 1. There existed a consistence between the STAT3 expression and the P-STAT3 level $(P=0.001)$, indicating the reliability and accuracy of our IHC analysis (Table 2).

\section{Correlation between the nuclear expression of STAT3 and clinicopathological parameters}

We observed the associations of the STAT3 nuclear expression with IPI score and molecular subtypes, but no statistical significances were reached $(P=0.099$ and $P=0.061$, respectively). No association was found between the STAT3 nuclear expression and other factors, including B symptoms, age of onset, clinical stage, and erythrocyte sedimentation rate (ESR), lactate dehydrogenase (LDH), and tumor size (Table 1).

\section{Association between the nuclear expression of STAT3 and overall survival}

Kaplan-Meier analysis showed that strong STAT3 nuclear expression was correlated with poorer OS $(P=$ 0.005) (Figure 2). Other factors such as serum LDH level, clinical stage, B symptoms, tumor size, and IPI 
Table 1 Clinicopathological parameters and their correlations with STAT3 nuclear expression

\begin{tabular}{|c|c|c|c|c|c|c|c|c|c|}
\hline \multirow[t]{2}{*}{ Clinical Parameters } & \multirow[t]{2}{*}{ No.\# } & \multicolumn{2}{|c|}{ Nuclear Staining } & \multirow[t]{2}{*}{$P$ Value } & \multirow[t]{2}{*}{ Clinical Parameters } & \multirow[t]{2}{*}{ No.\# } & \multicolumn{2}{|c|}{ Nuclear Staining } & \multirow[t]{2}{*}{$P$ Value } \\
\hline & & Low positive & Strong positive & & & & Low positive & Strong positive & \\
\hline Gender & & & & & Stage & & & & \\
\hline Male & 30 & 20 & 10 & 0.165 & $|\sim| \mid$ & 24 & 18 & 6 & 0.582 \\
\hline Female & 44 & 35 & 9 & & \|\|$\sim \| V$ & 50 & 37 & 13 & \\
\hline Age & & & & & $\mid \mathrm{PI}$ & & & & \\
\hline$<60$ & 55 & 43 & 12 & 0.161 & $0 \sim 2$ & 48 & 39 & 9 & 0.099 \\
\hline$\geq 60$ & 19 & 12 & 7 & & $3 \sim 4$ & 22 & 14 & 8 & \\
\hline B symptoms & & & & & Bulky mass & & & & \\
\hline positive & 29 & 23 & 6 & 0.306 & $\geq 10 \mathrm{~cm}$ & 9 & 6 & 3 & 0.440 \\
\hline negative & 45 & 32 & 13 & & $<10 \mathrm{~cm}$ & 55 & 47 & 16 & \\
\hline $\mathrm{LDH}$ & & & & & Molecular subtypes & & & & \\
\hline positive & 28 & 19 & 9 & 0.235 & GCB & 24 & 21 & 3 & 0.061 \\
\hline negative & 46 & 36 & 10 & & non-GCB & 50 & 34 & 16 & \\
\hline$\beta 2-M G$ & & & & & Treatment regimens & & & & \\
\hline positive & 46 & 34 & 12 & 0.513 & $\mathrm{CHOP}$ & 31 & 22 & 9 & \\
\hline negative & 17 & 12 & 5 & & $\mathrm{R}-\mathrm{CHOP}$ & 27 & 19 & 8 & \\
\hline ESR & & & & & & & & & \\
\hline positive & 38 & 28 & 10 & 0.406 & & & & & \\
\hline negative & 29 & 23 & 6 & & & & & & \\
\hline
\end{tabular}

score were also shown to be correlated with OS (data not shown) as reported in other studies, which confirmed our data is reliable. A forward stepwise multivariate Cox model analysis, incorporating the above factors, demonstrated that the nuclear expression of STAT3 $(P$ $=0.001)$, LDH level $(P=0.002)$ and tumor size $(P=$ 0.025 ) were independent prognostic factor for OS.

To analyze the prognostic implication of STAT3 in term of Rituximab therapy, we stratified all patients into two subgroups, the CHOP subgroup and the R-CHOP subgroup. In $\mathrm{CHOP}$ subgroup, high nuclear expression of STAT3 predicted poor survival $(P=0.001)$. In $\mathrm{R}$ CHOP subgroup, 2 of 19 cases died of DLBCL in low STAT3 cohort and 3 of 8 cases died in high STAT3 cohort. No significant association was observed between the expression of STAT3 and prognosis $(P=0.216)$ in the R-CHOP subgroup. But the survival curve showed that high STAT3 expression indicated poor OS in the first 40 months. Thus, it needs to increase the sample size to confirm this result (Table 3, Figure 3).

\section{Discussion}

Lam LT[15] et al. reported that activated B-cell diffuse large B-cell lymphoma (ABC-DLBCL) had higher level of STAT3 mRNA than that in GCB-DLBCL. Detection with immunohistochemistry [15] showed that slightly more cases with high nuclear expression of STAT3 were observed in the non-GCB DLBCL group and the high expression rates were $12.5 \%$ and $32.4 \%$ in GCB and non-GCB subtypes, respectively. However, no statistical significance was found. This is most likely due to the small sample size. Our study showed that the frequency of high nuclear expression of STAT3 in DLBCL was $25.7 \%$ with $12.5 \%$ in GCB subgroup and $32 \%$ in nonGCB subgroup, but not reaching significance $(P=$ 0.061).

Lam LT et al. [15] also demonstrated that high STAT3 expression in ABC-DLBCL patients correlated with inferior overall survival, but not with GCB-DLBCL patients. However, STAT3-high and STAT3-low subsets within ABC-DLBCL did not differ in prediction of overall survival. Our study showed that high nuclear expression of STAT3 in DLBCL possibly correlated with poor overall survival, especially in patients receiving $\mathrm{CHOP}$ regimen. This poor outcome may be explained at least in part by the multiple cellular functions of STAT3, which is a critical component of diverse signal transduction pathways[15,17,18]. STAT3 regulates the expression of a number of genes (e.g. survivin, bcl-xl, mcl-1) that modulate cell survival, differentiation, and proliferation (e.g. c-myc, cyclin D1, p21, cyclin E), invasion and metastasis (e.g. matrix metalloproteinase-9 and 2)[19], and angiogenesis (e.g. vascular endothelial growth factor) $[11,20,21]$. STAT3 can restrain anti-tumour immune responses [22-27] and regulate key cancer-promoting inflammatory mediators, which can initiate or promote oncogenic transformation, and genetic and epigenetic changes in malignant cells [28,29].

Our study also demonstrated the possibility of using immunohistochemistry to detect STAT3 expression in routine pathologic specimens, which may enable us conveniently to identify DLBCL cases with poor clinical 


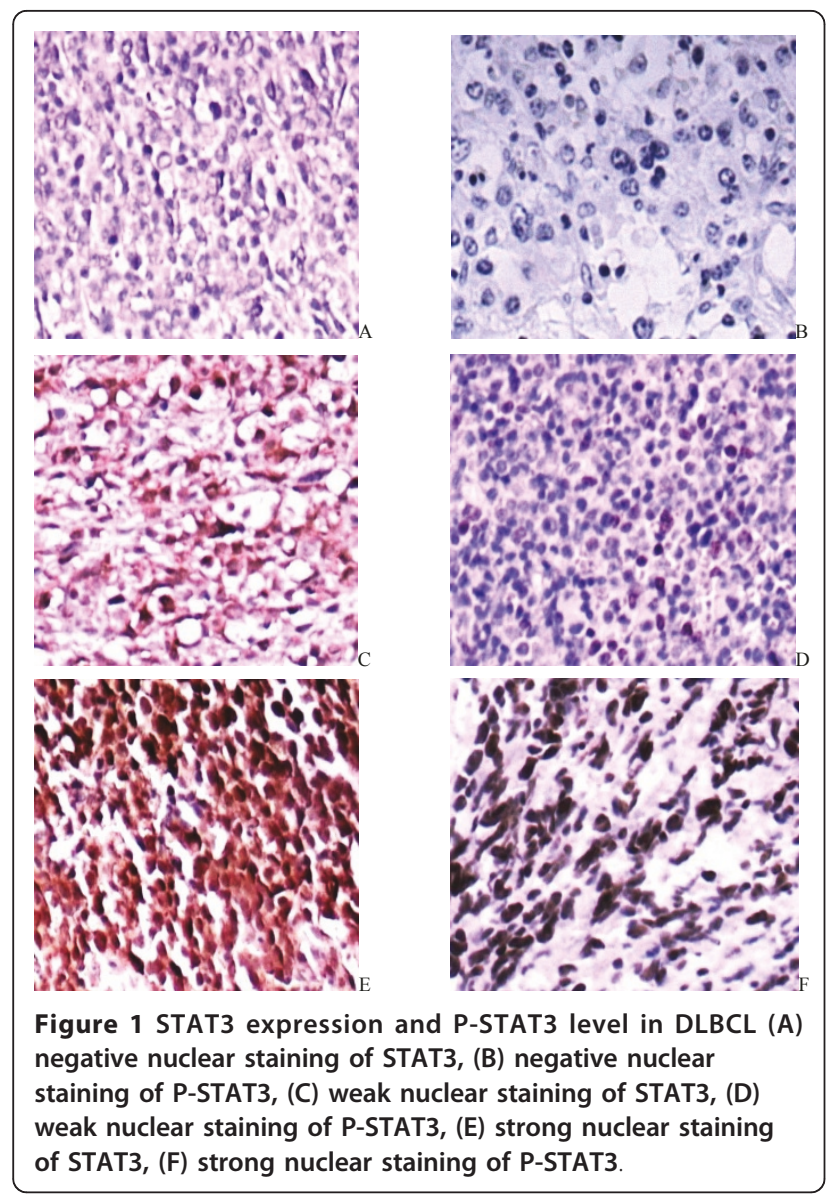

Table 2 Relationship between the STAT3 expression and the P-STAT3 level

\begin{tabular}{|c|c|c|c|c|c|}
\hline & & \multicolumn{2}{|c|}{$\begin{array}{l}\text { STAT3 expression in } \\
\text { nucleus }\end{array}$} & \multirow[t]{2}{*}{ Total } & \multirow[t]{2}{*}{$\begin{array}{l}P \\
\text { Value }\end{array}$} \\
\hline & & $\begin{array}{l}\text { Weak } \\
\text { positive }\end{array}$ & $\begin{array}{l}\text { Strong } \\
\text { positive }\end{array}$ & & \\
\hline \multirow[t]{2}{*}{$\begin{array}{l}\text { P- } \\
\text { STAT3 }\end{array}$} & Low positive & 43 & 7 & 50 & \\
\hline & $\begin{array}{l}\text { Strong } \\
\text { positive }\end{array}$ & 12 & 12 & 24 & 0.001 \\
\hline Total & & 55 & 19 & 74 & \\
\hline
\end{tabular}

Table 3 Correlation of STAT3 nuclear expression with overall survival

\begin{tabular}{lllll}
\hline treatment & STAT3 & OS & \multicolumn{2}{c}{ P } \\
\cline { 3 - 4 } & & positive & negative & \\
\hline CHOP & Low & 1 & 21 & 0.001 \\
\multirow{2}{*}{ R-CHOP } & High & 3 & 6 & \\
& Low & 2 & 17 & 0.216 \\
& High & 3 & 5 & \\
\hline
\end{tabular}

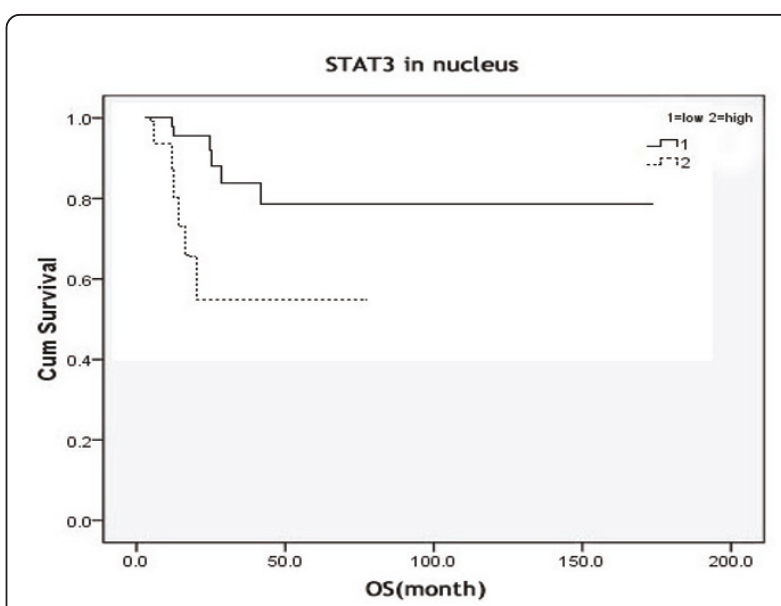

Figure 2 Kaplan-Meier curve of overall survival (OS) using STAT3 nuclear expression.

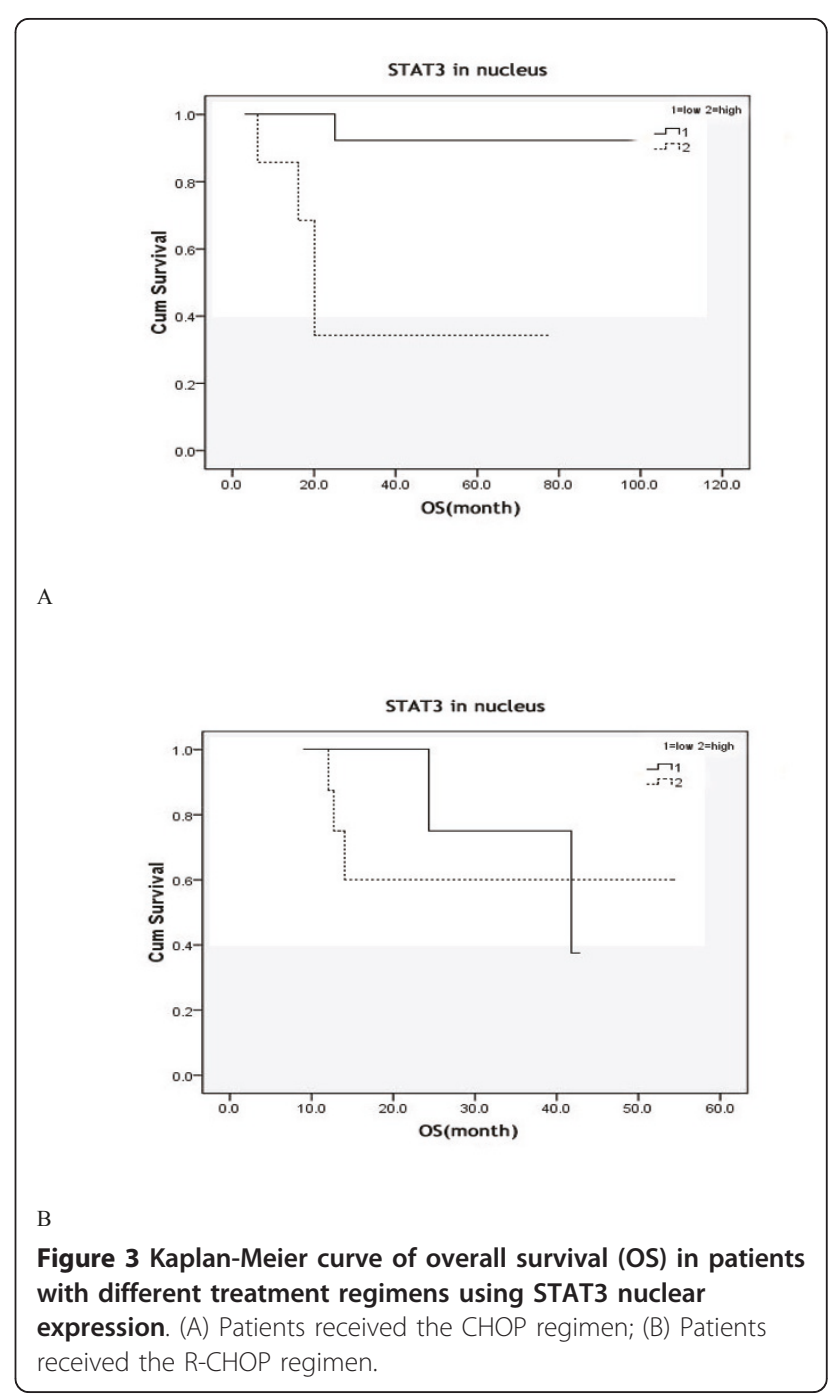


outcome, and subsequently guides us to adopt more intensive treatment for those patients.

Since STAT3 plays a critical role in tumor initiation and progression, inhibition of STAT3 activation would be an effective approach for cancer prevention and treatment. Our findings may provide a basis for the application of STAT3 inhibitors in the future.

\section{Grant Support}

This study was supported by the grant of the National Science Foundation Committee (NSFC) of China (No. 30973484)

\section{Acknowledgements}

We would like to thank the personnel from the Pathology Diagnosis Unit of Lymphoma at Peking University Health Science Center for their kind assistance in the IHC staining; Dr. Fan Zhou in Department of Pathology \& Laboratory Medicine at Southwest Washington Medical Center, Vancouver, for his kind help in English editing; and we thank Professor Wei Song in Central Laboratory of Beijing Cancer Hospital for her kind help in the final revision.

\section{Author details}

'Department of Lymphoma, Peking University School of Oncology, Beijing Cancer Hospital \& Institute; Key Laboratory of Carcinogenesis and Translational Research (Ministry of Education); Beijing 100142, China. ${ }^{2}$ Department of Pathology, Peking University School of Oncology, Beijing Cancer Hospital \& Institute; Key Laboratory of Carcinogenesis and Translational Research (Ministry of Education); Beijing 100142, China.

\section{Authors' contributions}

ZJ designed the study and reviewed the final manuscript; WZL collected and analyzed data, and drafted the manuscript; SYQ participated in the study design and helped draft the manuscript and reviewed the final manuscript; SYF helped the IHC staining. All authors read and approved the final manuscript.

\section{Conflicts of interests}

The authors declare that they have no competing interests.

Received: 5 May 2011 Accepted: 1 August 2011

Published: 1 August 2011

\section{References}

1. Swerdlow SH, Campo E, Harris NL, Jaffe ES, Pileri SA, Stein H, Thiele J, Vardiman JW, (Eds): World Health Organization Classification of Tumours of Haematopoietic and Lymphoid Tissues, IARC Press, Lyon; 2008.

2. Harris N L, Jaffe ES, Stein H, Banks PM, Chan JK, Cleary ML, Delsol G, De Wolf-Peeters C, Falini B, Gatter KC: A revised European-American classification of lymphoid neoplasms: a proposal from the International Lymphoma Study Group. Blood 1994, 84(5):1361-1392.

3. Sehn LH, Berry B, Chhanabhai M, Fitzgerald C, Gill K, Hoskins P, Klasa R, Savage KJ, Shenkier T, Sutherland J, Gascoyne RD, Connors JM: The revised International Prognostic Index (R-IPI) is a better predictor of outcome than the standard IPI for patients with diffuse large B-cell lymphoma treated with R-CHOP. Blood 2007, 109(5):1857-1861.

4. Talaulikar D, Shadbolt B, Dahlstrom JE, McDonald A: Routine use of ancillary investigations in staging diffuse large B-cell lymphoma improves the International Prognostic Index (IPI). J Hematol Oncol 2009, 22;2:49.

5. Alizadeh A A, Eisen MB, Davis RE, Ma C, Lossos IS, Rosenwald A, Boldrick JC, Sabet H, Tran T, Yu X, Powell Jl, Yang L, Marti GE, Moore T, Hudson J Jr, Lu L, Lewis DB, Tibshirani R, Sherlock G, Chan WC, Greiner TC, Weisenburger DD, Armitage JO, Warnke R, Levy R, Wilson W, Grever MR, Byrd JC, Botstein D, Brown PO, Staudt LM: Distinct types of diffuse large B-cell lymphoma identified by gene expression profiling. Nature 2000, 403:503-11.
6. Rosenwald A, Wright G, Chan WC, Connors JM, Campo E, Fisher RI, Gascoyne RD, Muller-Hermelink HK, Smeland EB, Giltnane JM, Hurt EM Zhao H, Averett L, Yang L, Wilson WH, Jaffe ES, Simon R, Klausner RD, Powell J, Duffey PL, Longo DL, Greiner TC, Weisenburger DD, Sanger WG, Dave BJ, Lynch JC, Vose J, Armitage JO, Montserrat E, López-Guillermo A, Grogan TM, Miller TP, LeBlanc M, Ott G, Kvaloy S, Delabie J, Holte H, Krajci P, Stokke T, Staudt LM, Lymphoma/Leukemia Molecular Profiling Project: The use of molecular profiling to predict survival after chemotherapy for diffuse large-B-cell lymphoma. N Engl J Med 2002, 346(25):1937-47.

7. Wright G, Tan B, Rosenwald A, Hurt EH, Wiestner A, Staudt LM: A gene expression-based method to diagnose clinically distinct subgroups of diffuse large B cell lymphoma. Proc Natl Acad Sci USA 2003, 100(17):9991-6.

8. Pfreundschuh $M$, Trümper $L$, Osterborg A, Pettengell R, Trneny M, Imrie K, Ma D, Gill D, Walewski J, Zinzani PL, Stahel R, Kvaloy S, Shpilberg O, Jaeger U, Hansen M, Lehtinen T, López-Guillermo A, Corrado C, Scheliga A, Milpied N, Mendila M, Rashford M, Kuhnt E, Loeffler M, MabThera International Trial Group: CHOP-like chemotherapy plus rituximab versus CHOP-like chemotherapy alone in young patients with good-prognosis diffuse large-B-cell lymphoma: a randomised controlled trial by the MabThera International Trial (MInT) Group. Lancet Oncol 2006, 7(5):379-91.

9. Sehn L H, Donaldson J, Chhanabhai M, Fitzgerald C, Gill K, Klasa R, MacPherson N, O'Reilly S, Spinelli JJ, Sutherland J, Wilson KS, Gascoyne RD, Connors JM: Introduction of combined CHOP plus rituximab therapy dramatically improved outcome of diffuse large B-cell lymphoma in British Columbia. J Clin Oncol 2005, 23(22):5027-33.

10. Calo' V, Migliavacca M, Bazan V, Macaluso M, Buscemi M, Gebbia N, Russo A: STAT proteins: from normal control of cellular events to tumorigenesis. J Cell Physiol 2003, 197:157-168.

11. Chen Z, Han ZC: STAT3: a critical transcription activator in angiogenesis. Med Res Rev 2008, 28(2):185-200.

12. Zhou Jianbiao, Goh Boon-Cher, Daniel HAlbert, Chen Shing Chien: ABT-869, a promising multi-targeted tyrosine kinase inhibitor:from bench to bedside. J Hematol Oncol 2009, 2:33-46.

13. Patrick BJohnston, Yuan RuiRong, Cavalli Franco, Thomas EWitzig: Targeted therapy of lymphoma. J Hematol Oncol 2010, 3:45.

14. Turkson J: STAT proteins as novel targets for cancer drug discovery. Expert Opin Ther Targets 2004, 8(5):409-22.

15. Lam LT, Wright G, Davis RE, Lenz G, Farinha P, Dang L, Chan JW, Rosenwald A, Gascoyne RD, Staudt LM: Cooperative signaling through the signal transducer and activator of transcription 3 and nuclear factor-B pathways in subtypes of diffuse large B-cell lymphoma. Blood 2008, 111(7):3701-13.

16. Scuto A, Kujawski M, Kowolik C, Krymskaya L, Wang L, Weiss LM, Digiusto D, Yu H, Forman S, Jove R: STAT3 Inhibition Is a Therapeutic Strategy for ABC-like Diffuse Large B-Cell Lymphoma. Cancer Res 2011, 71(9):3182-8.

17. Ding BB, Yu JJ, Yu RY, Mendez LM, Shaknovich R, Zhang Y, Cattoretti G, Ye BH: Constitutively activated STAT3 promotes cell proliferation and survival in the activated B-cell subtype of diffuse large B-cell lymphomas. Blood 2008, 111(3):1515-23.

18. Rane SG, Reddy EP: Janus kinases: components of multiple signaling pathways. Oncogene 2000, 19(49):5662-79.

19. Dechow T N, Pedranzini L, Leitch A, Leslie K, Gerald WL, Linkov I, Bromberg JF: Requirement of matrix metalloproteinase- 9 for the transformation of human mammary epithelial cells by Stat3-C. Proc Nat Acad Sci USA 2004, 101(29):10602-7.

20. Baran-Marszak F, Boukhiar M, Harel S, Laguillier C, Roger C, Gressin R, Martin A, Fagard R, Varin-Blank N, Ajchenbaum-Cymbalista F, Ledoux D: Constitutive and B-cell receptor-induced activation of STAT3 are important signaling pathways targeted by bortezomib in leukemic mantle cell lymphoma. Haematologica 2010, 95(11):1865-72.

21. Niu Guilian, Kenneth LWright: Constitutive Stat3 activity up-regulates VEGF expression and tumor angiogenesis. Oncogene 2002, 21:2000-2008.

22. Kujawski M, Kortylewski M, Lee $H$, Herrmann A, Kay H, Yu H: Stat3 mediates myeloid cell dependent tumor angiogenesis in mice. J Clin Invest 2008, 118:3367-3377.

23. Kortylewski M, Xin H, Kujawski M, Lee H, Liu Y, Harris T, Drake C, Pardoll D, $\mathrm{Yu}$ H: Regulation of the IL-23 and IL-12 balance by Stat3 signaling the tumor microenvironment. Cancer Cell 2009, 15:114-123.

24. Wang $L, Y i T$, Kortylewski M, Pardoll D, Zeng D, Yu H: IL-17 can promote tumor growth through an IL-6/Stat3 signaling pathway. J Exp Med 2009, 206:1457-1464. 
25. Cheng F, Wang HW, Cuenca A, Huang M, Ghansah T, Brayer J, Kerr WG, Takeda K, Akira S, Schoenberger SP, Yu H, Jove R, Sotomayor EM: A critical role for Stat3 signaling in immune tolerance. Immunity 2003, 19:425-436.

26. Yu H, Kortylewski M, Pardoll D: Crosstalk between cancer and immune cells: role of STAT3 in the tumour microenvironment. Nature Rev Immunol 2007, 7:41-51.

27. Yin Q, Zha X, Yang L, Chen S, Zhou Y, Wu X, Li Y: Generation of diffuse large B cell lymphoma-associated antigen-specific Va6/N $\beta 13+T$ cells by TCR gene transfer. J Hematol Oncol 2011, 4:2-9.

28. Haura E B, Turkson J, Jove R: Mechanisms of disease: insights into the emerging role of signal transducers and activators of transcription in cancer. Nature Clin Pract Oncol 2005, 2:315-324.

29. Mantovani A, Allavena P, Sica A, Balkwill F: Cancer-related inflammation. Nature 2008, 454:436-444.

doi:10.1186/1756-8722-4-31

Cite this article as: ZL et al:: High nuclear expression of STAT3 is associated with unfavorable prognosis in diffuse large B-cell lymphoma. Journal of Hematology \& Oncology 2011 4:31.

\section{Submit your next manuscript to BioMed Central} and take full advantage of:

- Convenient online submission

- Thorough peer review

- No space constraints or color figure charges

- Immediate publication on acceptance

- Inclusion in PubMed, CAS, Scopus and Google Scholar

- Research which is freely available for redistribution

Submit your manuscript at www.biomedcentral.com/submit 